\title{
Uninephrectomy in Rats on a Fixed Food Intake Potentiates Both Anorexia and Circulating Cytokine Subsets in Response to LPS
}

\author{
Denis Arsenijevic ${ }^{1,2 *}$ and Jean-Pierre Montani ${ }^{1,2}$ \\ ${ }^{1}$ Division of Physiology, Department of Medicine, University of Fribourg, Fribourg, Switzerland, ${ }^{2}$ National Center of \\ Competence in Research Kidney Control of Homeostasis (Kidney.CH), Zurich, Switzerland
}

\section{OPEN ACCESS}

Edited by:

Masaaki Murakami,

Hokkaido University, Japan

Reviewed by:

Daisuke Kamimura

Hokkaido University, Japan

Hideki Ogura,

Yale University, USA

${ }^{*}$ Correspondence:

Denis Arsenijevic

denis.arsenijevic@unifr.ch

Specialty section:

This article was submitted to Inflammation, a section of the journal Frontiers in Immunology

Received: 26 September 2015 Accepted: 07 December 2015

Published: 22 December 2015

Citation:

Arsenijevic D and Montani J-P (2015) Uninephrectomy in Rats on a Fixed Food Intake Potentiates Both Anorexia and Circulating Cytokine

Subsets in Response to LPS. Front. Immunol. 6:641. doi: 10.3389/fimmu.2015.00641
Recent human studies have suggested that mild reduction in kidney function can alter immune response and increase susceptibility to infection. The role of mild reduction in kidney function in altering susceptibility to bacterial lipopolysaccharide (LPS) responses was investigated in uninephrectomized rats compared to Sham-operated controls rats 4 weeks after surgery. Throughout the 4 weeks, all rats were maintained under mild food restriction at $90 \%$ of ad libitum intake to ensure the same caloric intake in both groups. In comparison to Sham, uninephrectomy (UniNX) potentiated LPS-induced anorexia by 2.1 -fold. The circulating anorexigenic cytokines granulocyte-macrophage colony stimulating factor, interferon- $\gamma$, tumor necrosis factor- $\alpha$, and complement-derived acylation-stimulating protein were elevated after LPS in UniNX animals compared to Sham animals. Interleukin(IL)1 $\beta$ and IL6 pro-inflammatory cytokines were transiently increased. Anti-inflammatory cytokines IL4 and IL10 did not differ or had a tendency to be lower in UniNX group compared to Sham animals. LPS-induced anorexia was associated with increased anorexigenic neuropeptides mRNA for pro-opiomelanocortin, corticotrophinreleasing factor, and cocaine-amphetamine-regulated transcript in the hypothalamus of both Sham and UniNX groups, but at higher levels in the UniNX group. Melanocortin-4receptor mRNA was markedly increased in the UniNX group, which may have contributed to the enhanced anorexic response to LPS of the UniNX group. In summary, UniNX potentiates pro-inflammatory cytokine production, anorexia, and selected hypothalamic anorexigenic neuropeptides in response to LPS.

Keywords: uninephrectomy, LPS, brain, cytokines, neuropeptides, anorexia, rats, Sprague-Dawley

\section{INTRODUCTION}

Chronic kidney disease is associated with an activation of the immune system and a chronic inflammatory state (1). Studies in kidney-transplant recipients have shown that there is a specificity of infections associated with reduced kidney function (2-4), but there is the confounding effect of immunosuppressive therapy. Thus, the situation concerning mild reduction

\footnotetext{
Abbreviations: ASP, acetylation-stimulating factor; C5L2, ASP receptor; CART, cocaine-amphetamine-regulated transcript; CRF, corticotrophin-releasing factor; GM-CSF, granulocyte-macrophage colony-stimulating factor; IFN $\gamma$, interferongamma; IL, interleukin; LPS, lipopolysaccharide; POMC, pro-opiomelanocortin; MC4R, melanocortin-4-receptor; UniNX, uninephrectomy.
} 
in kidney function and infection is less clear. A recent study in humans has suggested that mild or moderate chronic kidney disease increases the risk of postoperative infections (5). There are also data showing that mild reduction in kidney function in elderly persons is associated with increased circulating cytokines that are biomarkers for inflammation (6).

Infection activates host immune cells to produce cytokines. Susceptibility to acute bacterial Gram-negative infection can be mimicked by lipopolysaccharide (LPS) injection. LPS is used to induce pro-inflammatory cytokine production by immune cells. These cytokines are believed to be responsible in inducing pathology and metabolic alterations in LPS-injected mice (7). There is evidence that in humans, reduced kidney function augments immune cell cytokine production to LPS (8). LPS can induce anorexia when injected in the periphery (intraperitoneally) with several pro-inflammatory cytokines mediating this anorexia (9). However, cytokines injected directly into the brain (intracerebroventricularly) can also induce anorexia (10). It is generally believed that peripheral LPS induces peripheral cytokines, which then act on the brain on neurons that are involved in food intake regulation. We have previously shown that increased basal circulating cytokines (11) during a chronic infection results in excessive responses to LPS resulting in enhanced anorexia and hyperinduction of certain circulating cytokines. LPS/cytokines induce anorexia by acting on hypothalamic neural feeding pathways $(10,12,13)$. Hypothalamic anorexigenic neuropeptides involved in feeding are involved in LPS anorexia. These include pro-opiomelanocortin (POMC) (14), cocaine- and amphetamine-regulated transcript (CART) (15), corticotrophinreleasing factor (CRF) (16), and melanocortin-4-receptor (MC4R) $(17,18)$.

To test the hypothesis that mild reduction in kidney function increases the inflammatory and anorexic responses to LPS, we analyzed in uninephrectomized rats, compared to Sham-operated rats, the response to LPS on peripheral cytokines, on food intake, and on selected hypothalamic anorexigenic neuropeptides involved in food intake regulation. We used uninephrectomy (UniNX) because it is a model of mild reduction in kidney function (19) in contrast to other renal dysfunction models, such as 5/6 nephrectomy (20), which result generally in a greater degree of renal impairment with problems related to uremia and accumulation of toxic compounds.

\section{MATERIALS AND METHODS}

\section{Animal Preparation and Experimental Protocol}

\section{Animals and Diets}

All experimental protocols were approved by the Ethical Committee of the Veterinary Office of Fribourg, Switzerland. Male Sprague-Dawley rats were purchased from Elevage Janvier (Le Genest-St-Isle, France). Rats arrived at 5 weeks of age with an average weight of $160 \mathrm{~g} / \mathrm{animal}$. They were placed in individual cages and given pellet food and water ad libitum. After a week acclimation period, rats were either Sham operated or uninephrectomized (UniNX) by removal of the left kidney. After surgery, animals were put under a fixed food intake ( $90 \%$ of ad lib-fed diet) diet of normal chow paste. Dry food powder (Normal chow diet: Cat. No. 3433, Provimi-Kliba, Cossonay, Switzerland) was mixed with an equal amount of tap water, which was prepared daily ( $90 \mathrm{kcal} / \mathrm{rat})$ and given in food cups (9.00 a.m.-11.00 a.m.). We chose to put the rats under a fixed food intake ( $90 \%$ of ad lib-fed diet) to ensure the same caloric intake between Sham and UniNX rats. Ad $l i b$ feeding results in uncontrolled levels of nutrition, which can influence metabolites, hormones, inflammation, oxidative stress, and parameters of interest (21). Rats were kept in individual cages and had free access to water. The environmental temperature was maintained at $22 \pm 1^{\circ} \mathrm{C}$ in a room with a $12 \mathrm{~h}$ light/dark cycle (light 7.00 a.m. -7.00 p.m.).

\section{Surgery}

Left UniNX and Sham surgery were performed as previously described (19).

\section{Lipopolysaccharide Experimental Protocol}

Four weeks after surgery, Sham-operated (body weight $463 \pm 13 \mathrm{~g})$ and UniNX rats $(461 \pm 13 \mathrm{~g})$ were randomly separated into groups ( $n=8$ per group). Four groups of Shamoperated rats and four groups of UniNX rats were sacrificed for cytokine determination before and at $1.5,6$, and $24 \mathrm{~h}$ after intraperitoneal injection of $100 \mu \mathrm{g} / \mathrm{kg}$ LPS (E. coli 0111:B4, Sigma, Buchs, Switzerland) around 7 a.m., time T0 (Figure 1, group 1). Two additional groups (Sham and UniNX) were injected first intra-peritoneally with pyrogen free saline and 4 days later with LPS for food intake determination (Figure 1, group 2).

\section{Food Intake Determination}

Food was given to the rats only $6 \mathrm{~h}$ following the injection in order to allow sufficient time for the effects of LPS on food intake to develop (22). Food intake was then measured at 7.5, 12, and $24 \mathrm{~h}$ after saline or LPS injection.

\section{Blood and Brain Collection}

We collected serum and plasma (in EDTA or heparin-coated tubes) on ice and centrifuged at $4^{\circ} \mathrm{C}$ at $3,000 \mathrm{rpm}$ in a microcentrifuge. Serum and plasma were then kept at $-20^{\circ} \mathrm{C}$ until analyzed. The hypothalamic regions were cut out from the brain and then snap frozen in liquid nitrogen and stored at $-80^{\circ} \mathrm{C}$ until ready for

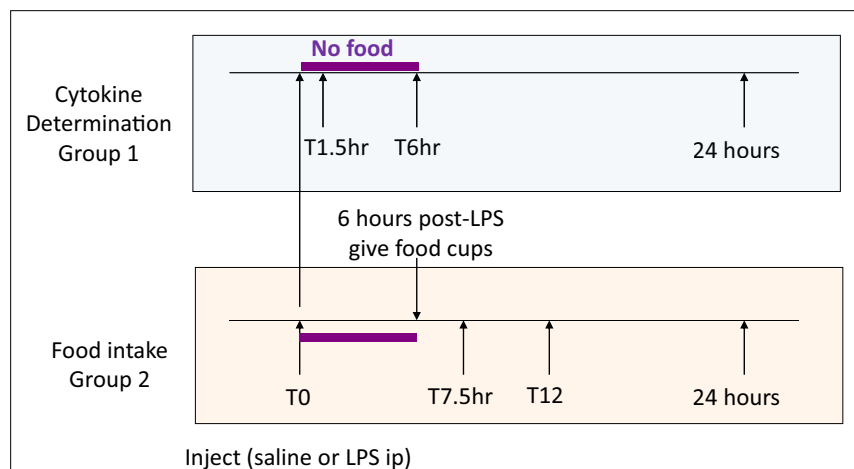

FIGURE 1 | Time lines for cytokine (group 1) and food intake (group 2) measurements. 
use in analysis. Tissues were pulverized in liquid nitrogen prior to analysis.

\section{Circulating Cytokines}

ELISA kits were purchased from eBioscience (San Diego, CA 92121, USA) for the following cytokines: interleukin-4, IL6, IL10, tumor necrosis factor alpha (TNF $\alpha$ ), interferon-gamma (IFN $\gamma$ ), and granulocyte macrophage colony stimulating factor (GMCSF). IL1 $\beta$ ELISA kit was purchased from R\&D systems, Abingdon, UK. Acylation-stimulating protein (ASP) was measured by ELISA from MyBiosource, San Diego, CA, USA.

\section{RT-PCR in Brain Hypothalamus}

After sacrificing, brain hypothalamic regions were cut out and placed in liquid nitrogen and then stored at $-80^{\circ} \mathrm{C}$. Total RNA was isolated as previously described (23). The RNA was then treated with DNase, after which it was reverse transcribed (Promega). Thereafter, we ran a RT-PCR. Samples were incubated in the iCycler instrument (BioRad, iCycler $\mathrm{iQ}^{\mathrm{m}}$, Version 3.1.7050) for an initial denaturation at $95^{\circ} \mathrm{C}$ for $3 \mathrm{~min}$, followed by 40 cycles of amplification. Each cycle consisted of $95^{\circ} \mathrm{C}$ for $10 \mathrm{~s}, 60$ or $62^{\circ} \mathrm{C}$ for $45 \mathrm{~s}$, and finally 95,55 , and $95^{\circ} \mathrm{C}$ for $1 \mathrm{~min}$ each. SybrGreen fluorescence emission was determined after each cycle. The relative amount of each mRNA was quantified using the iCycler software. Amplification of specific transcripts was confirmed by melting curve profiles generated at the end of each run. Cyclophilin was used as the control for each study and the relative quantification for a given gene was normalized to cyclophilin mRNA values. For a complete list of primers and their sources, see Table 1.

\section{Statistical Analysis}

Data are presented as means $\pm \mathrm{SE}$. Statistical analysis was performed using ANOVA Tukey-Kramer multiple comparison test. A value of $p<0.05$ was considered as significant.

\section{RESULTS}

\section{Food Intake}

During the light phase at 7.5 and $12 \mathrm{~h}$, food intake tended to be higher in UniNX-saline rats than in Sham-saline rats, but the difference was not statistically significant. Food intake in Sham-LPS and UniNX-LPS at these two time points were significantly reduced $(p<0.001)$ compared to their saline counterparts. No differences were observed between Sham-LPS and UniNX-LPS groups at the two time points. The majority of food intake for both Sham and UniNX occurred in the dark phase after $12 \mathrm{~h}$.

Cumulative food intake over $24 \mathrm{~h}$ in saline-Sham and salineUniNX rats was identical since both groups consumed $100 \%$ of their allotment of the isocaloric diet (Figure 2). LPS administration led to anorexia in both Sham and UniNX animals. LPS induced a $29 \%$ reduction in food intake in Sham animals relative to the Sham-saline control group (Figure 2). In UniNX, LPS induced a $62 \%$ reduction in food intake relative to the
TABLE 1 | RT-PCR primers.

\begin{tabular}{lll}
\hline $\begin{array}{l}\text { Primer } \\
\text { (source reference) }\end{array}$ & Sense $\mathbf{5}^{\prime} \mathbf{-} \mathbf{3}^{\prime}$ & Anti-sense $\mathbf{5}^{\prime} \mathbf{-} \mathbf{3}^{\prime}$ \\
\hline GM-CSFRa (24) & GCT GCA CCC GAT & GAA GGC GAA GGC \\
& GAC ATC & GTT GTC \\
IFNGRa (25) & TT GGA TGC TGC & AGT TCT TCC TGC \\
& TTG TTG CTC CTC & TCT CTG GTGCTT CT \\
C5L2 (26) & TTG CAG TGG CTT & GAT ACC TTG GTC \\
CART (27) & AGA AGA AGT ACG & CAC ACA GCT TCC \\
& GCC AAG TCC & CGA TCC \\
POMC (27) & CCT GTG AAG GTG & CAC GTT CTTGAT \\
& TAC CCC AAT GTC & GGC GT C \\
MC4R (27) & TAT GGT ACT GGA & TCA GAC GGA GGA \\
& GCG CGT AA & TGC TAT GA \\
CRF (28) & CTC TCT GGA TCT & CTA AAT GCA GAA \\
& CAC CTT CCA C & TCG TाT TGG C \\
Cyclophilin (29) & TCA GGG CTC TTG & CAG AAA ATC ACA \\
& AAG TCC C & GCA GCC ACC
\end{tabular}

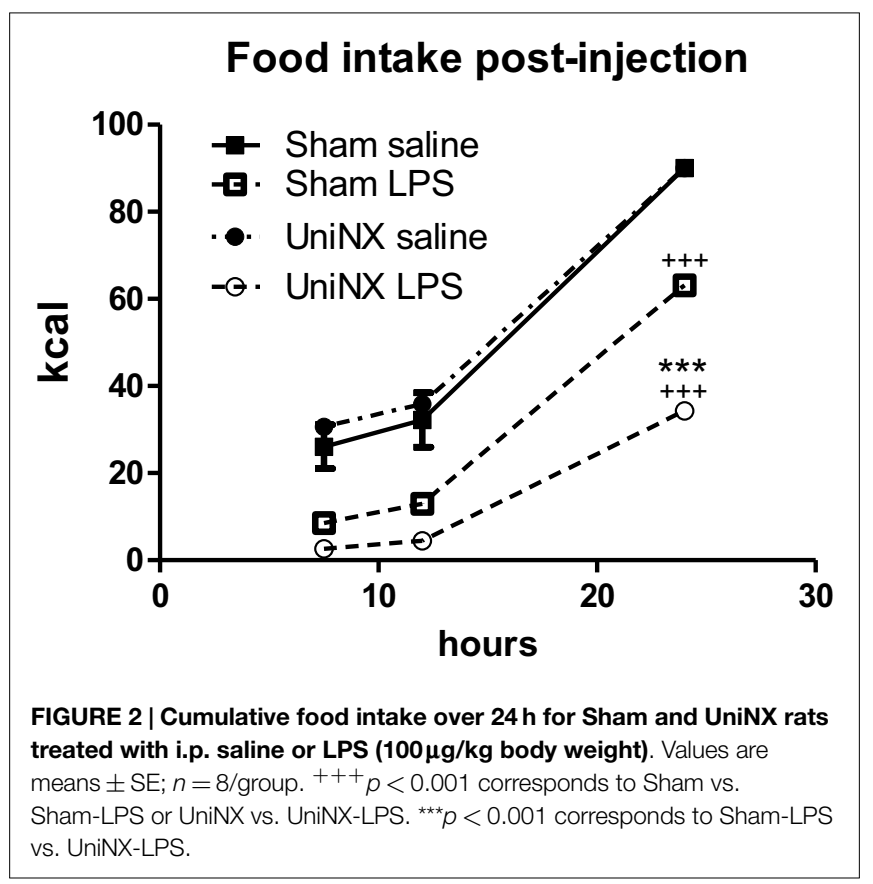

UniNX-saline control group (Figure 2). Thus, by the end of the 24-h period following LPS administration, UniNX had potentiated LPS anorexia 2.1-fold, relative to the Sham-LPS group (Figure 2).

\section{Circulating Cytokines}

The pro-inflammatory cytokines IL1 $\beta$ and IL6 showed a transient increase in UniNX group after LPS compared to Sham-LPS group (Figure 3). In contrast, anti-inflammatory cytokines IL4 and IL10 were stimulated and sustained up to $24 \mathrm{~h}$, although the response tended to be lower in the UniNX group (Figure 3). Basal circulating levels of ASP, GM-CSF, and IFN $\gamma$ were higher in the UniNX animals relative to the Sham group (Figure 4). 


\section{IL1 $\beta$}

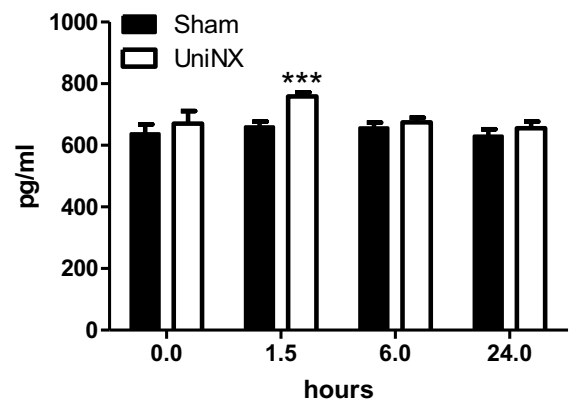

IL6

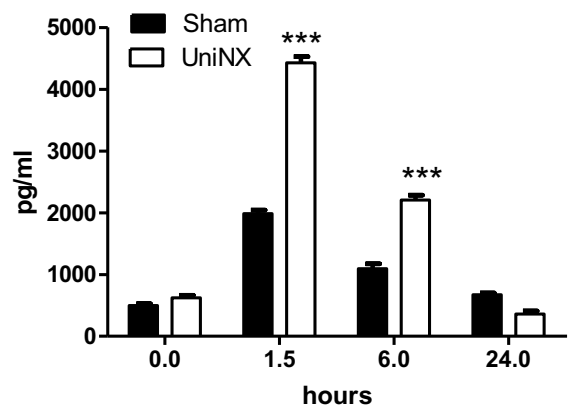

IL4
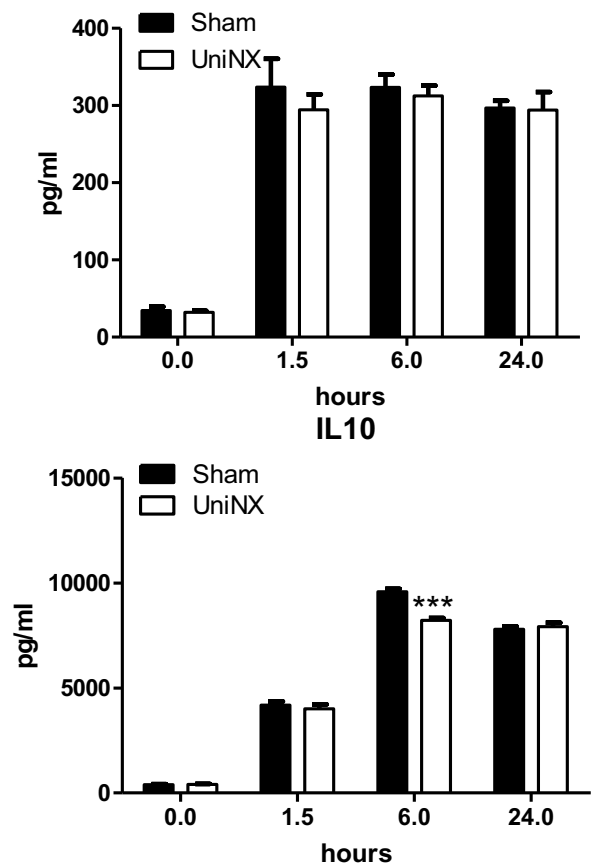

FIGURE 3 | Circulating levels of IL1ß, IL4, IL6, and IL10, in Sham-operated and UniNX rats at 0, 1.5, 6, and 24h after i.p. LPS injection. Values are means \pm SE; $n=8$ /group. ${ }^{* \star *} p<0.001$ corresponds to Sham vs. UniNX.

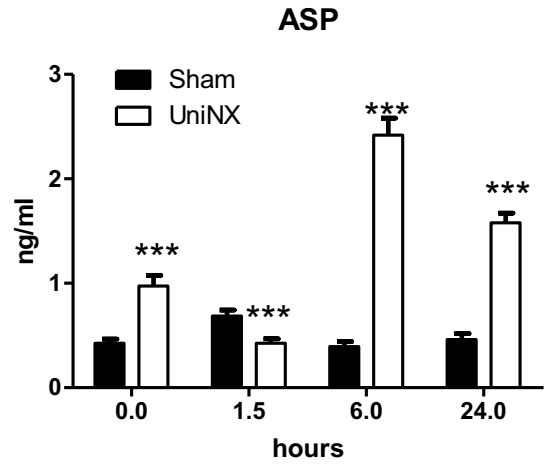

IFN $\gamma$

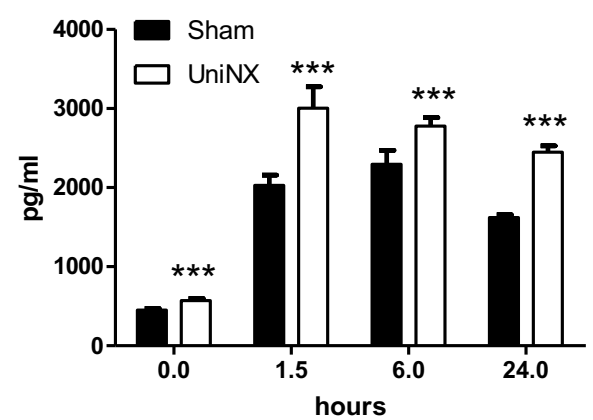

GM-CSF

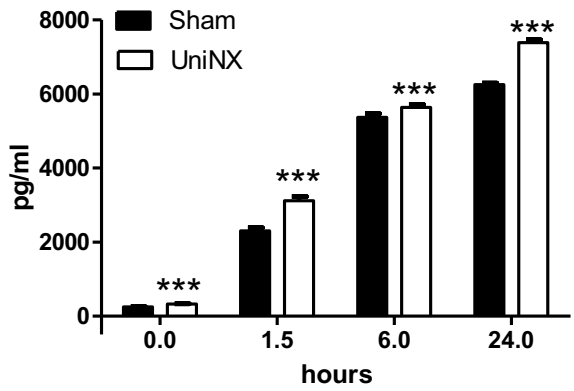

TNF $\alpha$

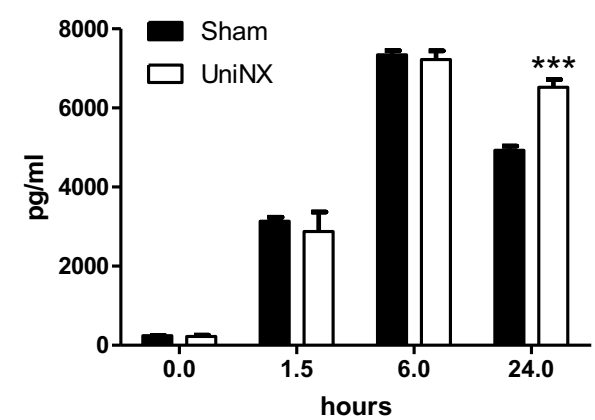

FIGURE 4 | Circulating levels of ASP, GM-CSF, IFN $\gamma$, and TNF $\alpha$, in Sham-operated and UniNX rats 1.5, 6, and $24 \mathrm{~h}$ after i.p. LPS injection. Values are means \pm SE; $n=8$ /group. ${ }^{\star \star *} p<0.001$ corresponds to Sham vs. UniNX. 
Each of these three anorexic cytokines and TNF $\alpha$ exhibited sustained increases for the 24-h period following the LPS injection, with the levels being significantly greater in UniNX animals relative to the LPS-treated Sham group $(p<0.001)$ (Figure 4).

\section{Hypothalamic Acylation-Stimulating Factor-Receptor (C5L2), GM-CSF- Receptor, and IFN $\gamma$-Receptor mRNA Levels}

Basal levels of hypothalamic C5L2, IFN $\gamma \mathrm{R}$, and GM-CSFR mRNA were significantly higher in UniNX than in Sham animals (Figure 5). Following LPS, the mRNA levels of these receptors remained significantly higher in UniNX than in the Sham group (Figure 5) with one exception (GM-CSFR at $6 \mathrm{~h}$ ).

\section{Hypothalamic Neuropeptides mRNA}

UniNX decreased the basal level of certain hypothalamic neuropeptide mRNAs. CART, CRF, and POMC mRNA levels were lower compared to Sham levels (Figure 6). In contrast, the level of MC4R mRNA was increased by UniNX (Figure 6). LPSpotentiated increases in all selected neuropeptides and MC4R measured in UniNX animals compared to Sham counterparts (Figure 6).

In general, LPS-induced higher levels of anorexigenic neuropeptides CART, CRF, and POMC (Figure 6). Furthermore, UniNX showed higher levels of these neuropeptides, which peaked at $6 \mathrm{~h}$ post-LPS (Figure 6). Twenty-four hour postLPS, these neuropeptides remained elevated in UniNX animals whereas they returned to basal levels in the Sham animals (Figure 6).

\section{DISCUSSION}

The major findings of our study are that UniNX potentiates both cytokine production and anorexia induced by LPS. In our previous study (19), we showed that UniNX led after 4 weeks to a $46 \%$ increase in plasma urea and a $47 \%$ increase in plasma cystatin $\mathrm{C}$ in comparison to Sham-operated controls. This corresponds to a $32 \%$ decrease in glomerular filtration rate (GFR), assuming a hyperbolic relationship between GFR and plasma cystatin C. We are thus studying a model of mild reduction of kidney function, in contrast to experimental models of more severe renal impairment.

Four weeks post-UniNX, basal levels of a subset of circulating cytokines, including IFN $\gamma$, GM-CSF, and the complement-derived ASP, were mildly elevated in the UniNX group compared to Sham animals as previously described (19). The low-level increases in basal IFN $\gamma$, GM-CSF, and ASP, however, did not affect total food intake over $24 \mathrm{~h}$ (fixed to $90 \%$ of ad libitum intake) in the UniNX animals compared to the Sham animals before LPS. The pro-inflammatory cytokines TNF $\alpha$, GM-CSF, IFN $\gamma$, and ASP were induced to higher levels by LPS in UniNX animals over $24 \mathrm{~h}$ compared to the Sham group. TNF $\alpha$ and IFN $\gamma$ have been shown to play an important role in LPS-induced anorexia $(9,30)$. Circulating ASP increases have been observed in kidney disease

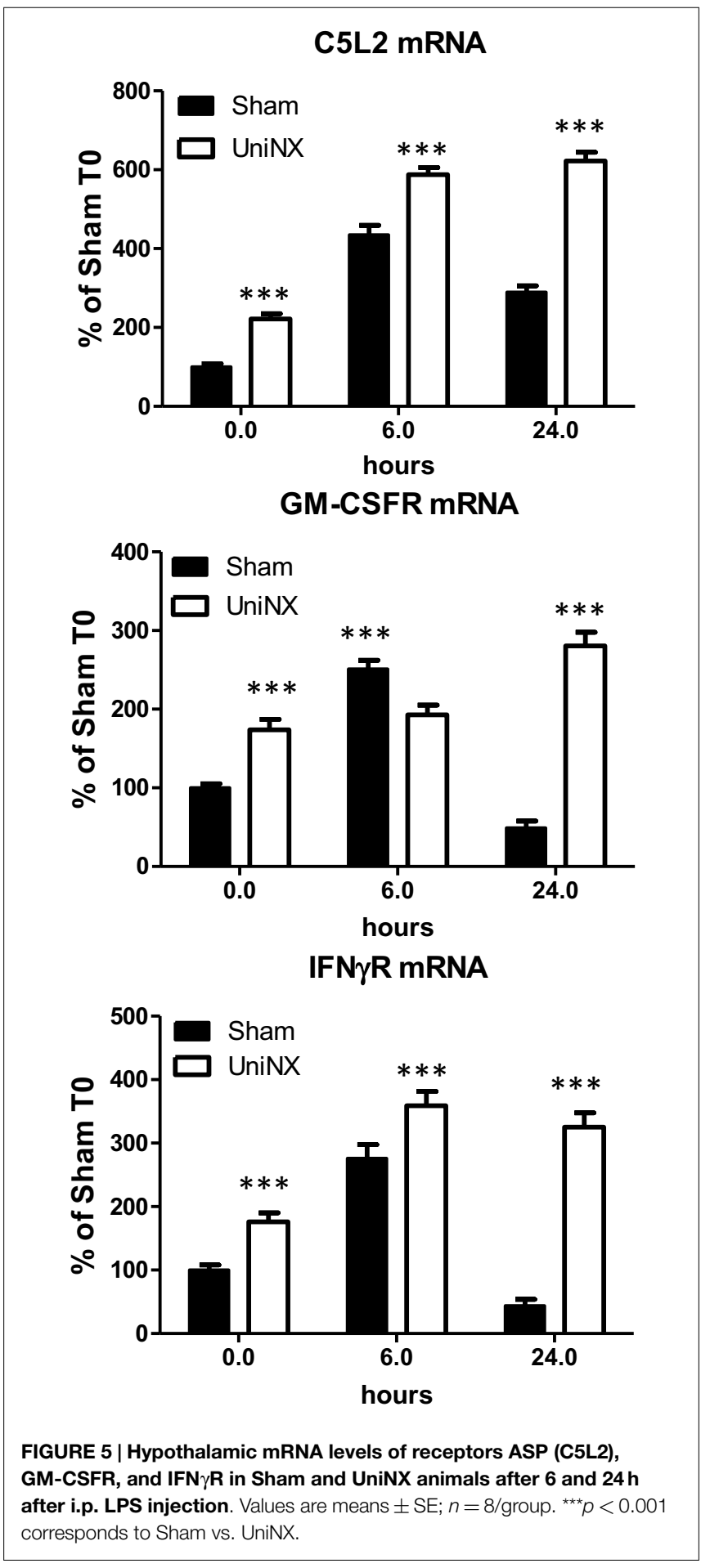

in humans (31-33) and can reduce body weight (34). Cytokines act on the brain to induce anorexia. This effect is believed to be mediated by an indirect action on blood vessels and the induction of cytokine production in the brain. Alternatively, they can act by gaining access to the brain and directly act on brain cells with respective cytokine receptors. Although these mechanisms have been described for $\operatorname{TNF} \alpha(9,35), \operatorname{IL} 1 \beta(36,37), \operatorname{IL6}(38)$, and their receptors $(9,39-43)$, the pathways for IFN $\gamma$, GM-CSF, 

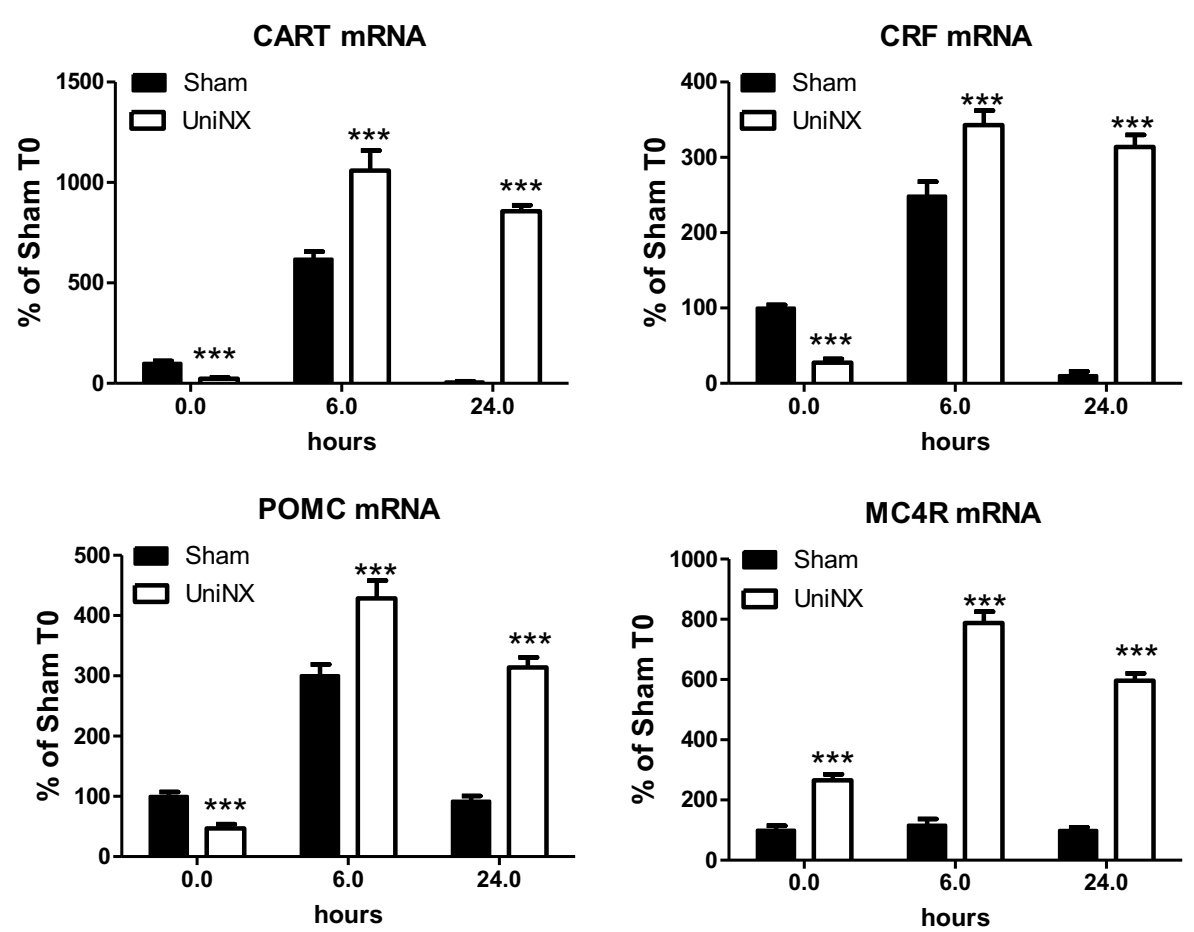

FIGURE 6 | Hypothalamic mRNA levels of anorexigenic neuropeptides CART, CRF, MC4R, and POMC in Sham and UniNX animals after 6 and $24 \mathrm{~h}$ after i.p. LPS injection. Values are means \pm SE; $n=8$ /group. ${ }^{\star \star \star} p<0.001$ corresponds to Sham vs. UniNX.

and ASP in the context of LPS anorexia, however, have not been established. Here we show that mRNAs for these receptors - ASP (C5L2), GM-CSFR, and IFN $\gamma \mathrm{R}$ are expressed in the hypothalamus suggesting that the brain can respond to these three immunemediators. Previous studies have shown that injection of ASP, GM-CSF, and IFN $\gamma$ within the cerebral ventricles resulted in anorexia $(34,44,45)$. LPS induces the three receptors to higher levels in the hypothalamus of UniNX animals compared to Sham group, suggesting that sensitivity to these cytokines may be altered in the brain. Other circulating pro-inflammatory cytokines in the UniNX group may play a role such as IL1 $\beta$ and IL6, even though they peak early and then return to basal or Sham levels by $24 \mathrm{~h}$. Interestingly, anti-inflammatory cytokines such as IL4 and IL10 had a tendency to be lower in the UniNX group in response to LPS. This may suggest that increased cytokine levels in the UniNX group may not be only the result of reduced cytokine clearance by the kidney. Reduced IL10 levels have also been reported in human kidney disease (46). Our data are consistent with the idea that reduced kidney function alters cytokines subsets and that cytokines are involved in pathology after nephrectomy (47). Potentiation of cytokine production by LPS also occurs in other models of disease including infection/inflammation $(48,49)$ and in human kidney disease (8). Neuropeptide potentiation has been shown to occur in anorexia nervosa (50) and bulimia nervosa (51).

Basal levels of anorexigenic neuropeptides CART, CRF, and POMC were decreased in UniNX animals compared to Shamoperated controls, whereas MC4R was increased. These observations are consistent with the fact that food intake data at 7.5 and $12 \mathrm{~h}$ post-saline in UniNX animals had a tendency to be a little bit higher. Higher circulating anorexic cytokines levels were observed after LPS in UniNX compared to Sham animals. This was associated with a more than twofold potentiation of the anorexic response to LPS in UniNX animals, relative to the Sham group. This differential increased anorexia in UniNX animals compared to Sham animals may be explained by increases in anorexigenic hypothalamic neuropeptides POMC, CRF, and CART mRNA levels. Our study is in agreement with other studies that LPS induces increases hypothalamic mRNA for POMC (52), CART $(53,54)$, and CRF $(16,52)$. Furthermore, i.c.v. injection of ASP has been shown to increase hypothalamic POMC mRNA (34). In rodent kidney disease, it has been shown that MC4R and POMC play a role in anorexia, modifying body composition, and this involves cytokines $(55,56)$. Our study suggests a role for mild reduction of kidney function in altering the basal levels of circulating cytokines and mRNA of brain neuropeptides (MC4R, POMC). Furthermore, basal hypothalamic neuropeptides levels have also been shown to be altered following UniNX. The consequence of these changes for body composition (19) requires additional investigation. Further attention is also required to determine why in the UniNX group LPS potentiates the transcriptional mRNA expression levels of all the measured neuropeptides, but not in Sham animals.

In summary, we show in young male rats that UniNX, a model of mild reduced kidney function, potentiates pro-inflammatory cytokine production, anorexia, and selected hypothalamic anorexigenic neuropeptides in response to LPS. This suggests that UniNX could alter susceptibility to infections. UniNX also alters basal inflammation, which involves a subset of 
circulating cytokines. These changes in cytokines could have several consequences on the host, beneficial or detrimental depending on the infection or the inflammatory process. This may also explain why there may be a specific profile of infections associated with kidney disease (57). Further evidence of altered immune response in patients with kidney disease may explain problems encountered with vaccination of patients (58). Therefore, any situation that depends on an immune response could have an impact on the host due to reduced kidney function.

\section{REFERENCES}

1. Ortega LM, Fornoni A. Role of cytokines in the pathogenesisof acute and chronic kidney disease, glomerulonephritis and end stage kidney disease. Int $J$ Intereferon Cytokine Mediator Res (2010) 2:49-62. doi:10.2147/IJICMR.S10111

2. Fishman JA, Rubin RH. Infection in organ-transplant recipients. N Engl J Med (1998) 338:1741-51. doi:10.1056/NEJM199806113382407

3. Naeini AE, Sharifi M, Shahidi S, Taheri S, Seirafian S, Taheri D, et al. Intestinal fungal and parasitic infections in kidney transplant recipients: a multi-center study. Saudi J Kidney Dis Transpl (2012) 23:677-83. doi:10.4103/1319-2442. 98110

4. Barsoum RS. Parasitic infections in organ transplantation. Exp Clin Transplant (2004) 2:258-67.

5. Minakata K, Bando K, Tanaka S, Takanashi S, Konishi H, Miyamoto Y, et al. Preoperative chronic kidney disease as a strong predictor of postoperative infection and mortality after coronary artery bypass grafting. Circ J (2014) 78:2225-31. doi:10.1253/circj.CJ-14-0328

6. Keller CR, Odden MC, Fried LF, Newman AB, Angleman S, Green CA. Kidney function and markers of inflammation in elderly persons without chronic kidney disease: the health, aging, and body composition study. Kidney Int (2007) 71:239-44. doi:10.1038/sj.ki.5002042

7. Johnson RW. Inhibition of growth by pro-inflammatory cytokines: an integrated view. J Anim Sci (1997) 75:1244-55.

8. Mantuano E, Santi S, Filippi C, Manca-Rizza G, Paoletti S, Consani C, et al. Simvastatin and fluvastatin reduce interleukin-6 and interleukin-8 lipopolysaccharide (LPS) stimulated production by isolated human monocytes from chronic kidney disease patients. Biomed Pharmacother (2007) 61:360-5. doi:10.1016/j. biopha.2007.03.002

9. Arsenijevic D, Garcia I, Vesin C, Vesin D, Arsenijevic Y, Seydoux J, et al. Differential roles of tumor necrosis factor-alpha and interferon-gamma in mouse hypermetabolic and anorectic responses induced by LPS. Eur Cytokine Netw (2000) 11:662-8.

10. Plata-Salaman CR. Cytokine-induced anorexia. Behavioral, cellular, and molecular mechanisms. Ann N Y Acad Sci (1998) 856:160-70. doi:10.1111/j.17496632.1998.tb08324.x

11. Arsenijevic D, Girardier L, Seydoux J, Pechere JC, Garcia I, Lucas R, et al. Metabolic-cytokine responses to a second immunological challenge with LPS in mice with T. gondii infection. Am J Physiol (1998) 274:E439-45.

12. Hrupka BJ, Langhans W. A role for serotonin in lipopolysaccharide-induced anorexia in rats. Pharmacol Biochem Behav (2001) 68:355-62. doi:10.1016/ S0091-3057(00)00463-9

13. Inui A. Cancer anorexia-cachexia syndrome: are neuropeptides the key? Cancer Res (1999) 59:4493-501.

14. Gayle D, Ilyin SE, Flynn MC, Plata-Salaman CR. Lipopolysaccharide (LPS)- and muramyl dipeptide (MDP)-induced anorexia during refeeding following acute fasting: characterization of brain cytokine and neuropeptide systems mRNAs. Brain Res (1998) 795:77-86. doi:10.1016/S0006-8993(98)00280-7

15. Sergeyev V, Broberger C, Hokfelt T. Effect of LPS administration on the expression of POMC, NPY, galanin, CART and $\mathrm{MCH}$ mRNAs in the rat hypothalamus. Brain Res Mol Brain Res (2001) 90:93-100. doi:10.1016/S0169328X(01)00088-2

16. Rorato R, Castro M, Borges BC, Benedetti M, Germano CM, AntunesRodrigues J, et al. Adrenalectomy enhances endotoxemia-induced hypophagia: higher activation of corticotrophin-releasing-factor and proopiomelanocortin

\section{AUTHOR CONTRIBUTIONS}

Conceived and designed the experiments: DA, J-PM. Performed the experiments: DA. Analyzed the data: DA, J-PM. Wrote paper: DA, J-PM. Edited manuscript: DA, J-PM.

\section{ACKNOWLEDGMENTS}

The study was supported by Swiss National Center of Competence in Research (NCCR-Kidney.CH) grant to J-PM.

hypothalamic neurons. Horm Behav (2008) 54:134-42. doi:10.1016/j.yhbeh. 2008.02.011

17. Borges BC, Rorato R, Avraham Y, da Silva LE, Castro M, Vorobiav L, et al. Leptin resistance and desensitization of hypophagia during prolonged inflammatory challenge. Am J Physiol Endocrinol Metab (2011) 300:E858-69. doi:10.1152/ ajpendo.00558.2010

18. Sartin JL, Marks DL, McMahon CD, Daniel JA, Levasseur P, Wagner CG, et al. Central role of the melanocortin-4 receptors in appetite regulation after endotoxin. J Anim Sci (2008) 86:2557-67. doi:10.2527/jas.2008-0916

19. Arsenijevic D, Cajot JF, Dulloo AG, Montani JP. Uninephrectomy in rats on a fixed food intake results in adipose tissue lipolysis implicating spleen cytokines. Front Physiol (2015) 6:195. doi:10.3389/fphys.2015.00195

20. Gai Z, Chu L, Hiller C, Arsenijevic D, Penno CA, Montani JP, et al. Effect of chronic renal failure on the hepatic, intestinal, and renal expression of bile acid transporters. Am J Physiol Renal Physiol (2014) 306:F130-7. doi:10.1152/ ajprenal.00114.2013

21. Diamond JR. Effects of dietary interventions on glomerular pathophysiology. Am J Physiol (1990) 258:F1-8.

22. von Meyenburg C, Langhans W, Hrupka BJ. Evidence for a role of the 5-HT2C receptor in central lipopolysaccharide-, interleukin-1 beta-, and leptin-induced anorexia. Pharmacol Biochem Behav (2003) 74:1025-31. doi:10.1016/S00913057(03)00030-3

23. Arsenijevic D, Girardier L, Seydoux J, Chang HR, Dulloo AG. Altered energy balance and cytokine gene expression in a murine model of chronic infection with Toxoplasma gondii. Am J Physiol (1997) 272:E908-17.

24. Joshi PC, Applewhite L, Mitchell PO, Fernainy K, Roman J, Eaton DC, et al. GMCSF receptor expression and signaling is decreased in lungs of ethanol-fed rats. Am J Physiol Lung Cell Mol Physiol (2006) 291:L1150-8. doi:10.1152/ajplung. 00150.2006

25. Wang Y, Ren Z, Tao D, Tilwalli S, Goswami R, Balabanov R. STAT1/IRF1 signaling pathway mediates the injurious effect of interferon-gamma on R. oligodendrocyte progenitor cells. Glia (2010) 58:195-208. doi:10.1002/glia. 20912

26. Francis K, Lewis BM, Monk PN, Ham J. Complement C5a receptors in the pituitary gland: expression and function. J Endocrinol (2008) 199:417-24. doi: 10.1677/JOE-08-0110

27. Lopez N, Sanchez J, Pico C, Palou A, Serra F. Dietary l-leucine supplementation of lactating rats results in a tendency to increase lean/fat ratio associated to lower orexigenic neuropeptide expression in hypothalamus. Peptides (2010) 31:1361-7. doi:10.1016/j.peptides.2010.03.028

28. Li XF, Kinsey-Jones JS, Knox AMI, Wu XQ, Tahsinsoy D, Brain SD. Neonatal lipopolysaccharide exposure exacerbates stress-induced suppression of luteinizing hormone pulse frequency in adulthood. Endocrinology (2007) 148:5984-90. doi:10.1210/en.2007-0710

29. Summermatter S, Marcelino H, Arsenijevic D, Buchala A, Aprikian O, Assimacopoulos-Jeannet F, et al. Adipose tissue plasticity during catch-up fat driven by thrifty metabolism: relevance for muscle-adipose glucose redistribution during catch-up growth. Diabetes (2009) 58:2228-37. doi:10.2337/db081793

30. Car BD, Eng VM, Schnyder B, Ozmen L, Huang S, Gallay P, et al. Interferon gamma receptor deficient mice are resistant to endotoxic shock. J Exp Med (1994) 179:1437-44. doi:10.1084/jem.179.5.1437

31. Fujita T, Hemmi S, Kajiwara M, Yabuki M, Fuke Y, Satomura A, et al. Complement-mediated chronic inflammation is associated with diabetic 
microvascular complication. Diabetes Metab Res Rev (2013) 29:220-6. doi:10. $1002 /$ dmrr. 2380

32. Ozata M, Oktenli C, Gulec M, Ozgurtas T, Bulucu F, Caglar K, et al. Increased fasting plasma acylation-stimulating protein concentrations in nephrotic syndrome. J Clin Endocrinol Metab (2002) 87:853-8. doi:10.1210/jcem.87.2.8243

33. Tang JH, Wen Y, Wu F, Zhao XY, Zhang MX, Mi J, et al. Increased plasma acylation-stimulating protein in pediatric proteinuric renal disease. Pediatr Nephrol (2008) 23:959-64. doi:10.1007/s00467-007-0738-1

34. Roy C, Roy MC, Gauvreau D, Poulin AM, Tom FQ, Timofeeva E, et al. Acute injection of ASP in the third ventricle inhibits food intake and locomotor activity in rats. Am J Physiol Endocrinol Metab (2011) 301:E232-41. doi:10.1152/ ajpendo.00476.2010

35. McCoy MK, Tansey MG. TNF signaling inhibition in the CNS: implications for normal brain function and neurodegenerative disease. J Neuroinflammation (2008) 5:45. doi:10.1186/1742-2094-5-45

36. Rivest S. How circulating cytokines trigger the neural circuits that control the hypothalamic-pituitary-adrenal axis. Psychoneuroendocrinology (2001) 26:761-88. doi:10.1016/S0306-4530(01)00064-6

37. Bellavance MA, Rivest $S$. The neuroendocrine control of the innate immune system in health and brain diseases. Immunol Rev (2012) 248:36-55. doi:10. 1111/j.1600-065X.2012.01129.x

38. Erta M, Quintana A, Hidalgo J. Interleukin-6, a major cytokine in the central nervous system. Int J Biol Sci (2012) 8:1254-66. doi:10.7150/ijbs.4679

39. Utsuyama M, Hirokawa K. Differential expression of various cytokine receptors in the brain after stimulation with LPS in young and old mice. Exp Gerontol (2002) 37:411-20. doi:10.1016/S0531-5565(01)00208-X

40. Vallieres L, Rivest S. Regulation of the genes encoding interleukin-6, its receptor, and gp130 in the rat brain in response to the immune activator lipopolysaccharide and the proinflammatory cytokine interleukin-1beta. J Neurochem (1997) 69:1668-83. doi:10.1046/j.1471-4159.1997.69041668.x

41. Cao C, Matsumura K, Shirakawa N, Maeda M, Jikihara I, Kobayashi S, et al. Pyrogenic cytokines injected into the rat cerebral ventricle induce cyclooxygenase- 2 in brain endothelial cells and also upregulate their receptors. Eur J Neurosci (2001) 13:1781-90. doi:10.1046/j.0953-816x.2001.01551.x

42. Wei SG, Zhang ZH, Beltz TG, Yu Y, Johnson AK, Felder RB. Subfornical organ mediates sympathetic and hemodynamic responses to bloodborne proinflammatory cytokines. Hypertension (2013) 62:118-25. doi:10. 1161/HYPERTENSIONAHA.113.01404

43. Wei SG, Yu Y, Zhang ZH, Felder RB. Proinflammatory cytokines upregulate sympathoexcitatory mechanisms in the subfornical organ of the rat. Hypertension (2015) 65:1126-33. doi:10.1161/HYPERTENSIONAHA.114.05112

44. Reed JA, Clegg DJ, Smith KB, Tolod-Richer EG, Matter EK, Picard LS, et al. GM-CSF action in the CNS decreases food intake and body weight. JClin Invest (2005) 115:3035-44. doi:10.1172/JCI25681

45. Plata-Salaman CR. Interferons and central regulation of feeding. Am J Physiol (1992) 263:R1222-7.

46. Akchurin OM, Kaskel F. Update on inflammation in chronic kidney disease. Blood Purif (2015) 39:84-92. doi:10.1159/000368940

47. Park SW, Chen SW, Kim M, Brown KM, Kolls JK, D’Agati VD, et al. Cytokines induce small intestine and liver injury after renal ischemia or nephrectomy. Lab Invest (2011) 91:63-84. doi:10.1038/labinvest.2010.151
48. Tisoncik JR, Korth MJ, Simmons CP, Farrar J, Martin TR, Katze MG. Into the eye of the cytokine storm. Microbiol Mol Biol Rev (2012) 76:16-32. doi:10.1128/ MMBR.05015-11

49. Delfanti F, Veglia F, Poli G, Lazzarin A, Biswas P. Ex vivo modulation of RANTES and sCD30 by proinflammatory stimuli in HIV-seropositive and negative individuals. Clin Immunol (2000) 97:102-8. doi:10.1006/clim.2000. 4923

50. Stoving RK, Hangaard J, Hansen-Nord M, Hagen C. A review of endocrine changes in anorexia nervosa. J Psychiatr Res (1999) 33:139-52. doi:10.1016/ S0022-3956(98)00049-1

51. Kaye W. Neurobiology of anorexia and bulimia nervosa. Physiol Behav (2008) 94:121-35. doi:10.1016/j.physbeh.2007.11.037

52. Grinevich V, Ma XM, Herman JP, Jezova D, Akmayev I, Aguilera G. Effect of repeated lipopolysaccharide administration on tissue cytokine expression and hypothalamic-pituitary-adrenal axis activity in rats. J Neuroendocrinol (2001) 13:711-23. doi:10.1046/j.1365-2826.2001.00684.x

53. Duan K, Yu W, Lin Z, Tan S, Bai X, Gao T, et al. Insulin ameliorating endotoxaemia-induced muscle wasting is associated with the alteration of hypothalamic neuropeptides and inflammation in rats. Clin Endocrinol (2015) 82:695-703. doi:10.1111/cen.12610

54. Fuzesi T, Sanchez E, Wittmann G, Singru PS, Fekete C, Lechan RM. Regulation of cocaine- and amphetamine-regulated transcript-synthesising neurons of the hypothalamic paraventricular nucleus by endotoxin; implications for lipopolysaccharide-induced regulation of energy homeostasis. J Neuroendocrinol (2008) 20:1058-66. doi:10.1111/j.1365-2826.2008.01758.x

55. Cheung WW, Mak RH. Melanocortin antagonism ameliorates muscle wasting and inflammation in chronic kidney disease. Am J Physiol Renal Physiol (2012) 303:F1315-24. doi:10.1152/ajprenal.00341

56. Mak RH, Cheung W, Cone RD, Marks DL. Orexigenic and anorexigenic mechanisms in the control of nutrition in chronic kidney disease. Pediatr Nephrol (2005) 20:427-31. doi:10.1007/s00467-004-1789-1

57. Sarnak MJ, Jaber BL. Mortality caused by sepsis in patients with end-stage renal disease compared with the general population. Kidney Int (2000) 58:1758-64. doi:10.1111/j.1523-1755.2000.00337.x

58. Mathew R, Mason D, Kennedy JS. Vaccination issues in patients with chronic kidney disease. Expert Rev Vaccines (2014) 13:285-98. doi:10.1586/14760584. 2014.874950

Conflict of Interest Statement: The authors declare that the research was conducted in the absence of any commercial or financial relationships that could be construed as a potential conflict of interest.

The Reviewer Daisuke Kamimura and the Handling Editor, Masaaki Murakami declare their shared affiliation and the Handling Editor states that the review process nevertheless met the standards of a fair and objective review.

Copyright ( $\odot 2015$ Arsenijevic and Montani. This is an open-access article distributed under the terms of the Creative Commons Attribution License (CC BY). The use, distribution or reproduction in other forums is permitted, provided the original author(s) or licensor are credited and that the original publication in this journal is cited, in accordance with accepted academic practice. No use, distribution or reproduction is permitted which does not comply with these terms. 